\title{
Proposta de diretrizes para o desenvolvimento de instrumentos avaliativos para software educativo
}

\author{
Proposal of guidelines for the development of evaluation instruments for educational \\ software
}

Katia Alexandra de Godoi, Stephania Padovani

diretrizes, instrumentos avaliativos, software educativo

\begin{abstract}
Neste artigo, propõem-se diretrizes para o desenvolvimento de instrumentos avaliativos para software educativo, com base nos resultados de um estudo analítico de vinte e três instrumentos avaliativos, de pesquisa realizada com professores e de dois grupos focados. Primeiramente, descrevem-se instrumentos avaliativos direcionados para softwares educativos, para então tratar da necessidade de que o desenvolvimento desses instrumentos seja centrado nos usuários. Em seguida, apresentamos os procedimentos metodológicos da pesquisa, e por fim as diretrizes para o desenvolvimento de instrumentos avaliativos direcionados para softwares educativos.
\end{abstract}

guidelines, evaluation instrument, educational software

In this study, we proposed guidelines for the development of evaluation instruments for educational software, based on the results of an analytical study of twenty three evaluation instruments, of a survey conducted with teachers and of two focus groups. Firstly, evaluation instruments for educational software are described and the need for user-centred instruments is addressed. Then, we present the research method, and propose guidelines for the development of evaluation instruments aimed at educational software.

\section{Introdução}

A necessidade de que os educadores conheçam e saibam utilizar instrumentos para seleção e avaliação de softwares educativos vem sendo apontada por diversos autores. Squires \& Preece [1999], por exemplo, acreditam que o uso de software educativo requer que o professor decida qual software usar, para qual propósito e em qual situação.

No entanto, conforme adverte Freire [2005], esse tipo de avaliação é bastante complexa. A autora argumenta que as especificidades do software educativo fazem com que este produto deva ser avaliado de modo mais focado e tendo como base não apenas características técnicas, mas também, características ligadas à educação. Mais ainda, para avaliar um software educativo, 0 pesquisador precisa dispor de ferramentas mais complexas que instrumentos avaliativos gerais, ou seja, instrumentos avaliativos direcionados para softwares educativos.

Existem vários instrumentos avaliativos direcionados para software educativo, encontrando-se a maioria na literatura de IHC (interação humano-computador). Apesar da área ser bastante explorada por pesquisadores, observam-se algumas lacunas nos estudos que lidam com instrumentos avaliativos de softwares educativos. Vale ressaltar que, dentre os vinte e três trabalhos consultados nesta pesquisa, nenhum menciona a participação dos usuários e poucos são os autores que apresentam validação dos instrumentos propostos em situação real de uso.

Ao adotar uma abordagem de design da informação centrado no usuário, este artigo visa contribuir para o preenchimento das lacunas mencionadas, envolvendo diretamente professores na utilização de instrumentos avaliativos de software educativo. Neste contexto, este estudo tem como objetivo propor diretrizes para viabilizar a aplicação de instrumentos avaliativos de software educativo por professores do ensino fundamental e médio.

Inicialmente, apresentamos uma breve descrição dos instrumentos direcionados para avaliação de softwares educativos, para então tratar da necessidade desses instrumentos serem centrados 
nos usuários. Em seguida, descrevemos o método da pesquisa, e por fim as diretrizes para o desenvolvimento de instrumentos avaliativos direcionados para softwares educativos. Cumpre destacar, que o presente artigo visa apresentar e facilitar o entendimento e utilização das diretrizes no desenvolvimento / aplicação de instrumentos avaliativos, os resultados de cada uma das fases do método da pesquisa estão publicados em Godoi [2009] e Godoi \& Padovani [2009].

\section{Instrumentos avaliativos para software educativo}

Conforme explicam Shiratuddin \& Landoni [2002], na maioria dos artigos acadêmicos e livros sobre avaliação de sistemas, dois tipos de avaliação são freqüentemente mencionados: formativo e somativo. A avaliação formativa é um contínuo processo conduzido ao longo de todos os passos do desenvolvimento do software educativo, tornando-se uma parte essencial desse processo. Por outro lado, a avaliação somativa geralmente é aplicada no final do produto, ou quando o produto já está pronto e disponível no mercado. Squires \& Preece [1999] sugerem ainda um prognóstico de avaliação, isto é, a avaliação do software antes de seu uso pretendido, quando os professores estão planejando lições ou tomando decisões de compra.

Instrumentos avaliativos para software educativo apresentam grande diversidade no que tange ao formato, critérios de avaliação utilizados, ênfase na coleta de dados, forma de avaliação e apresentação dos resultados. A seguir, apresentamos uma síntese desses parâmetros.

No que se refere ao formato, os resultados obtidos por Godoi \& Padovani [2009] demonstraram que os instrumentos avaliativos de softwares educativos aparecem nas seguintes modalidades: checklists, diretrizes, escalas de avaliação (figura 1), formulários, híbridos (figura 2), modelo conceitual, questionários (figura 3) ou sistemas.

Figura 1: Exemplo de escala de avaliação [com base em Reeves e Harmon, 1996]

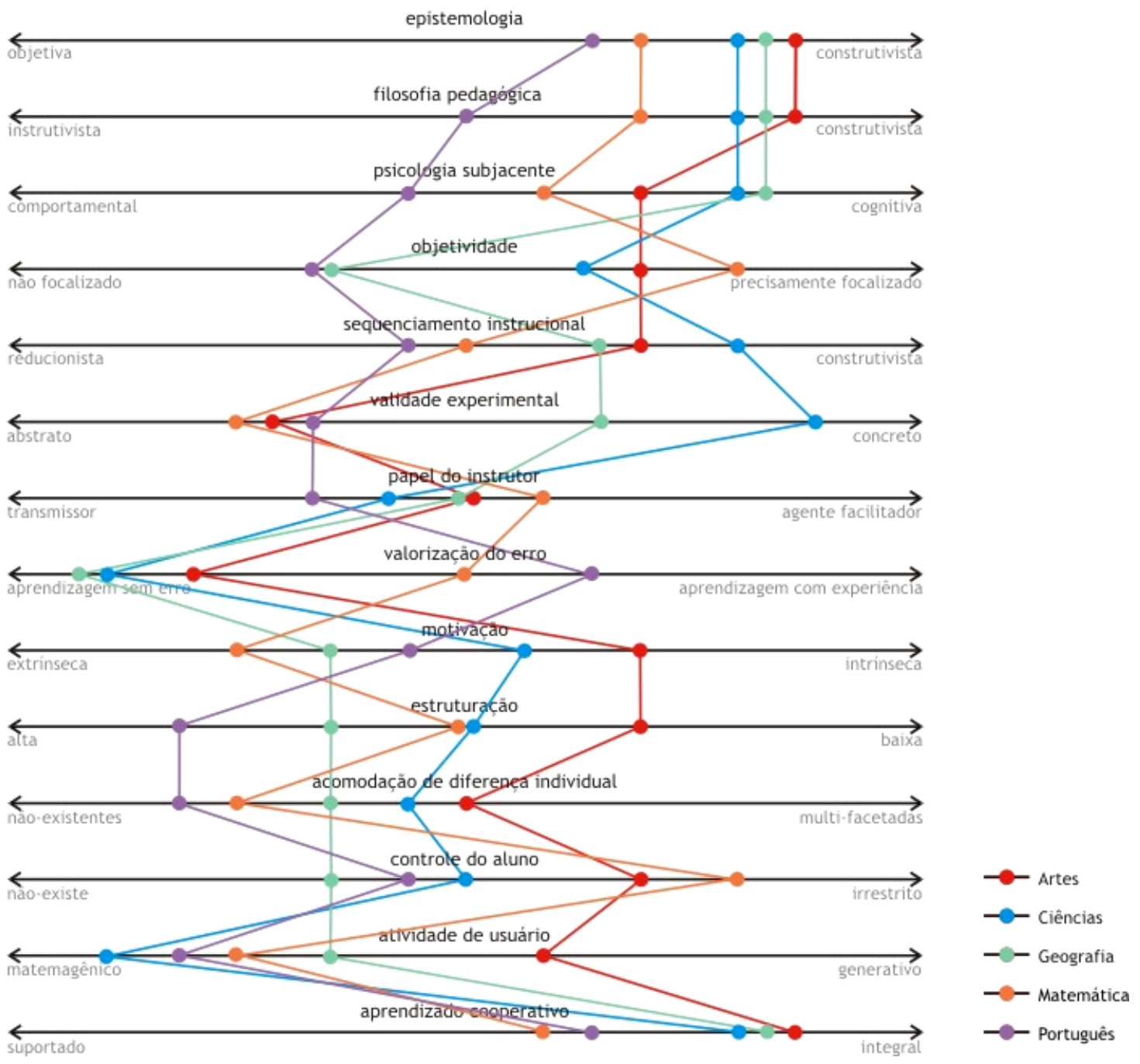


Figura 2: Exemplo de instrumento híbrido com perguntas fechadas e escalas [Campos, 1994]

\section{Processo de avaliação:}

Assinale na escala o valor que lhe parece melhor representar o grau com que o critério foi atingido.

\& Possui elementos motivadores?

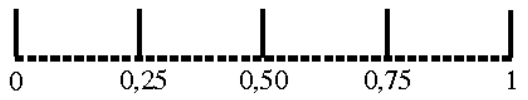

Processo de avaliação:

Para este critério, utiliza-se uma medida binária de resposta ao indicador:

^ Existe manual do usuário?

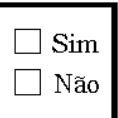

Figura 3: Exemplo de questionário com perguntas abertas [Costa, 1999]

\begin{tabular}{|c|c|}
\hline \multicolumn{2}{|r|}{ IDENTIFICAÇÃO DO PRODUTO } \\
\hline TÍTULO & \\
\hline EDITORA & \\
\hline DATA DE EDIÇÃO & \\
\hline MANUAIS DE EXPLORAÇÃO & A aplicação inclui manuais de exploração? \\
\hline TIPOS DE SOFTWARE & Tendo como base as diferentes tipologias de sof tware, como se pode classificar esta aplicação? \\
\hline CONTEÚDO & $\begin{array}{l}\text { Qual é o conteúdo principal a bordado na aplicação? } \\
\text { Que outros conteúdos indui? }\end{array}$ \\
\hline NÍVEL ETÁRIO & Em que idade a aplicação pode ser preferencialmente utilizada? \\
\hline NÍVEL DE ENSINO & Para que nível ou nive is de ensino parece ser mais a dequada? \\
\hline ÁREA CURRICULAR & $\begin{array}{l}\text { Em que disciplinas ou áreas disciplinares pode ser utilizada? Para abordar que tópicos concretos } \\
\text { do aurriculo? A que necessidades de aprendizagem pode responder? }\end{array}$ \\
\hline & AVALIAÇÃO ENQUANTO FERRAMENTA DE APRENDIZAGEM \\
\hline $\begin{array}{l}\text { ADEQUACCÃO E RELEVÂNCIA } \\
\text { CURRICULAR } \\
\text { (Que articulação se pode } \\
\text { estabelecer entre a aplicação } \\
\text { e o curńculo?) }\end{array}$ & $\begin{array}{l}\text { A aplicação é relevante e útil para a área curricular em que pode ser utilizada? } \\
\text { Os objetivos e o conteúdo da aplicação podem integrar-se com facilidade no curriculo? } \\
\text { Em que medida permite satisfazer objetivos do currícub? } \\
\text { Contém elementos diferencia dores relativamente a outros recursos e materiais didáticos que a } \\
\text { tornam potenciadora do processo de aprendizagem? } \\
\text { Traz vanta gens relativamente a outros meios altemativos? } \\
\text { A aplicação permite uma utilização curricular de natureza transdisciplinar? } \\
\text { A organização dos conteúdos pode influenciar positivamente a aprendizagem? }\end{array}$ \\
\hline
\end{tabular}

Quanto aos critérios de avaliação empregados nestes instrumentos, os mesmos podem ser enquadrados nas 3 (três) categorias propostas por Silva [2002]: critérios ergonômicos (utilizar o material didático digital com o máximo de segurança, conforto e produtividade), pedagógicos (estratégias didáticas de apresentação das informações e tarefas cognitivas exigidas em conformidade com objetivo educacional e características do aprendiz) e comunicacionais (dispositivos midiáticos de comunicação entre os interlocutores eficazes) (figura 4). 
Figura 4: Critérios de avaliação separados em categorias [com base em Silva, 2002]

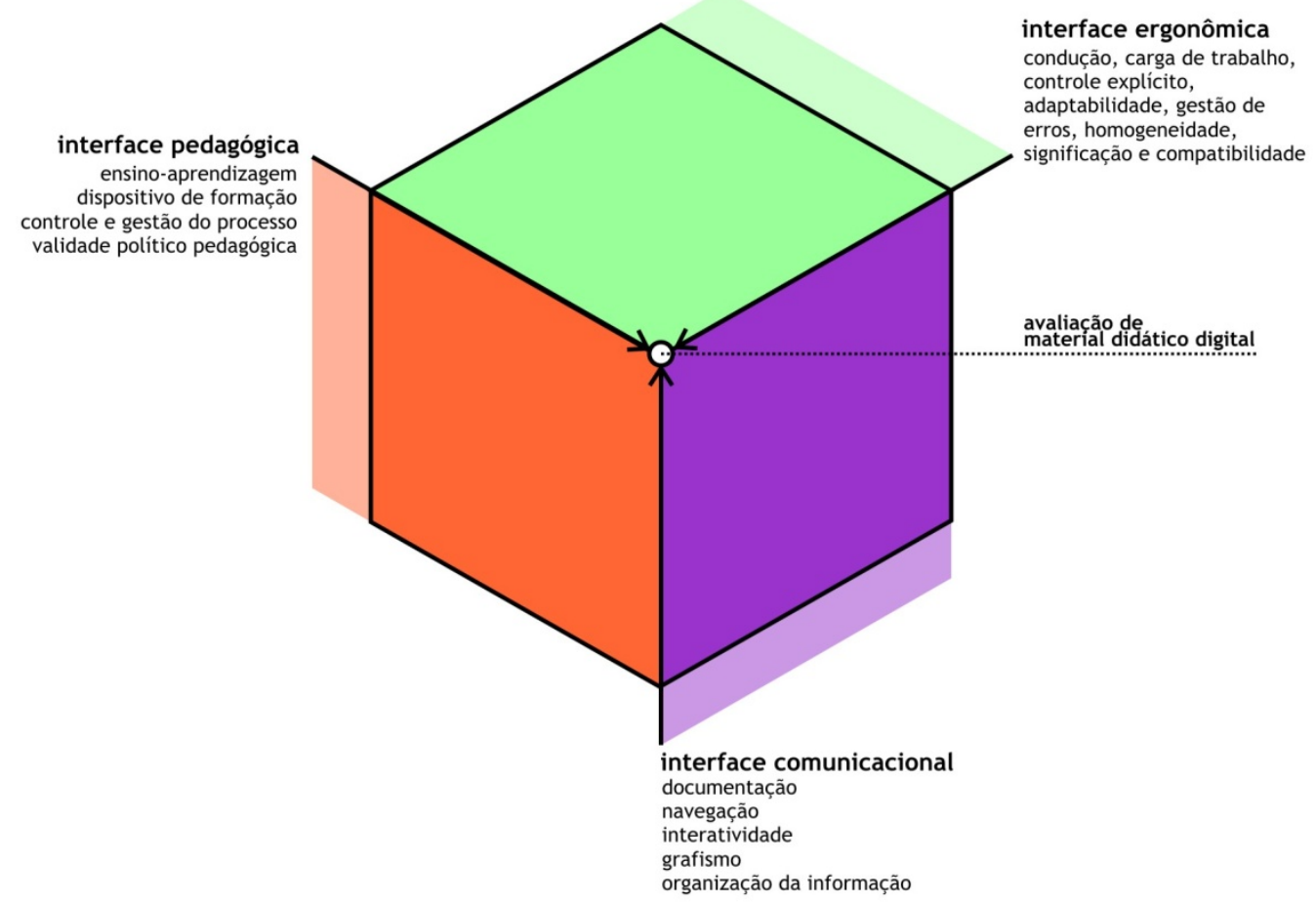

Os critérios ergonômicos/ comunicacionais mais freqüentes são: controle do utilizador, documentação/ materiais de apoio, feedback imediato, flexibilidade, funcionalidade geral, gestão de erros, identificação do software, legibilidade, qualidade nas opções de ajuda e usabilidade da interface. Já os critérios pedagógicos mais freqüentes são: avaliação da aprendizagem, conteúdo (p. ex. clareza, qualidade) e motivação.

Observamos também durante o estudo analítico, que a maior parte dos instrumentos utiliza mais de uma forma de avaliação do software em cada uma das questões, variando entre: atribuição de conceito, atribuição de peso/ valor, binária (sim ou não), diferencial semântico (figura 5), escala de intensidade (figura 6), escala numerada (figura 7), múltipla escolha, nota, pergunta encadeada e relato escrito; sendo que as mais freqüentes são: escala de intensidade e relato escrito.

Figura 5: Exemplo de diferencial semântico na forma de avaliação em cada uma das questões [Buckleitner, 1998]

$$
\begin{aligned}
& \text { Poor } \quad \text { Good } \\
& 1+\frac{7}{3} \overline{4} \frac{}{5} \overline{6} \frac{7}{7} \frac{}{9} \frac{10}{10}
\end{aligned}
$$

Figura 6: Exemplo de escala de intensidade na forma de avaliação em cada uma das questões [ISTE, 2002]

Content is current.

Content is thorough.

Content is age appropriate.

Content is reliable.

Content is clear.

Content is fully referenced.

$\begin{array}{rr}\text { No } & \text { Some } \\ \text { No } & \text { Some } \\ \text { No } & \text { Some } \\ \text { No } & \text { Some } \\ \text { No } & \text { Some } \\ \text { No } & \text { Some }\end{array}$

$\begin{array}{rr}\text { Mostly } & \text { Yes } \\ \text { Mostly } & \text { Yes } \\ \text { Mostly } & \text { Yes } \\ \text { Mostly } & \text { Yes } \\ \text { Mostly } & \text { Yes } \\ \text { Mostly } & \text { Yes }\end{array}$


Figura 7: Exemplo de escala numerada na forma de avaliação em cada uma das questões [Campos, 1994]

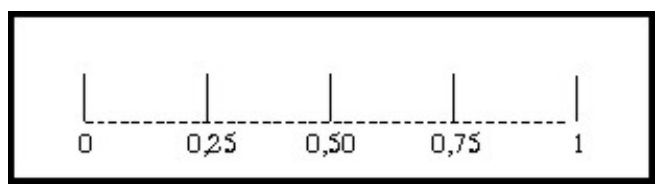

A ênfase na coleta de dados dos instrumentos está dividida entre quantitativa e qualitativa. Os instrumentos trazem também diversas formas de apresentação das informações na fase de preenchimento: campos de preenchimento (figura 8), diferencial semântico, escala sem numeração, escala numerada, quadros binários, quadros múltipla escolha, tabela (figura 9) e texto (figura 10); dentre as formas de apresentação das informações, o texto e a tabela merecem destaque.

Figura 8: Exemplo de campos de preenchimento na apresentação da informação no preenchimento [Schrock, 2000]

\begin{tabular}{|r|r|r|r|r|r|}
\hline Category of the Software & Simulation & & Tutorial & \\
\hline Presentation & & Tool/ Authoring & & Drill and practice & \\
\hline Reference & & Word processing & & Standard add ressed: \\
\hline Image editing & & & & \\
\hline
\end{tabular}

Figura 9: Exemplo de tabela na apresentação da informação no preenchimento [Silva, 2002]

\begin{tabular}{|c|c|c|c|c|c|}
\hline \multicolumn{6}{|c|}{ Marque a opção de sejada com o número 1 (um) } \\
\hline \multicolumn{2}{|c|}{ Elementos Itens } & \multirow[t]{2}{*}{ Sim } & \multirow[t]{2}{*}{ Não } & \multirow[t]{2}{*}{ N/A } & \multirow[t]{2}{*}{ Nota } \\
\hline 01 & Critérios Ergonômicos & & & & \\
\hline 01.01 & Condução & & & & \\
\hline 01.01. A & Para presteza & & & & \\
\hline A1 & $\begin{array}{l}\text { O programa disponibiliza informação necessária, poupando } \\
\text { o usuário de aprender por tentativa e erro as tarefas e } \\
\text { operaçס̃es de comando requeridas? }\end{array}$ & & & & \\
\hline $\bar{A} 2$ & $\begin{array}{l}\text { O programa disponibiliza um glossário para auxiliar o } \\
\text { usuário na compreensão de termos técnicos? }\end{array}$ & & & & \\
\hline A3 & $\begin{array}{l}\text { Existem recursos como hipertexto, áudio e vídeo } \\
\text { apropria dos que facilitem a compreensão dos conteúdos? }\end{array}$ & & & & \\
\hline$\overline{A 4}$ & $\begin{array}{l}\text { O programa disponibiliza recursos visuais como ampulheta, } \\
\text { relógio ou barra de progressão para informar o usuário dos } \\
\text { resultados de uma ação de forma que ele possa } \\
\text { acompanhar sua evolução? }\end{array}$ & & & & \\
\hline \multirow[t]{2}{*}{ A5 } & $\begin{array}{l}\text { O programa apresenta títulos, nas caixas de diálogo, } \\
\text { formulários, campos de entrada de dados, janelas, etc. } \\
\text { localizados no alto da tela, centrados e justificados à } \\
\text { esquerda? }\end{array}$ & & & & \\
\hline & Conformidade & & & & \\
\hline
\end{tabular}

Figura 10: Exemplo de espaço para texto na apresentação da informação no preenchimento [ISTE, 2002]

DESCRIBE THE LEARNING STRATEGY INCORPORATED IN THE DESIGN: (Either here or on ano ther page)

Por fim, a tabulação/ totalização dos resultados varia entre: atribuição de média, atribuição de peso, atribuição de porcentagem, atribuição de valor, interpretação da nota (figura 11), relato escrito; sendo que a forma de tabulação/ totalização dos resultados mais freqüente aparece na 
forma de relato escrito. $E$ a apresentação das informações na fase de tabulação dos resultados pode variar entre: perfil em diferencial semântico, gráfico (figura 12), planilha eletrônica, tabela e texto; merecendo destaque o texto.

Figura 11: Exemplo de interpretação de nota na tabulação/ totalização dos resultados [Campos, 1994]

\begin{tabular}{|l|l|}
\hline Valor da Medida & Interpretação \\
\hline $0.95-1.00$ & Alta qualidade do software. \\
\hline $0.90-0.94$ & $\begin{array}{l}\text { Qualidade boa, devendo-se resolver em paralelo os problemas } \\
\text { detectados. }\end{array}$ \\
\hline $0.60-0.89$ & $\begin{array}{l}\text { Qualidade mediana, problemas existentes resultaram em um } \\
\text { produto final pobre e com custos elevados. }\end{array}$ \\
\hline $0.00-0.59$ & $\begin{array}{l}\text { Sem qualidade, problemas existentes não justificam o uso do } \\
\text { produto. O produto deve ser alterado e/ou revisto. }\end{array}$ \\
\hline
\end{tabular}

Figura 12: Exemplo de gráfico na apresentação da informação na fase de tabulação dos resultados [Gamez, 1998]

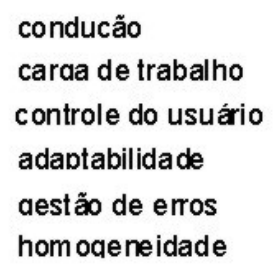

91

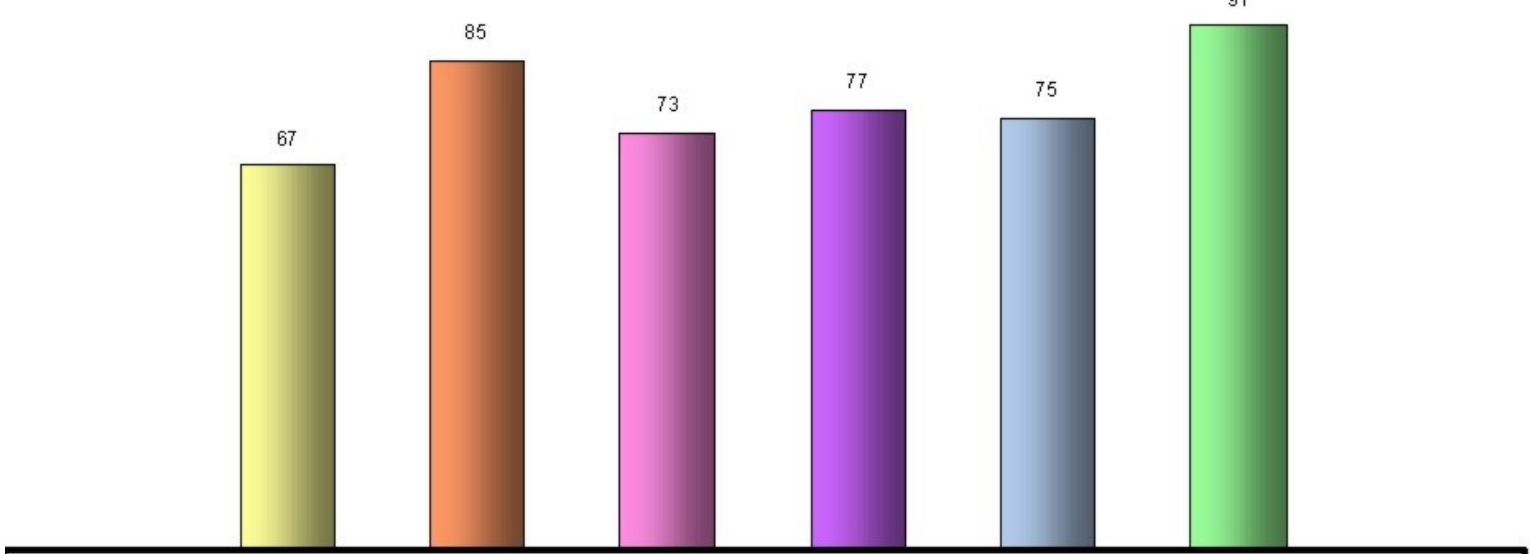

A partir dos itens tratados no estudo analítico, verificamos de modo geral que:

(1) formato - aparecem em 8 (oito) modalidades;

(2) critérios de avaliação - os instrumentos avaliativos usam os critérios ergonômicos, pedagógicos e comunicacionais;

(3) ênfase na coleta de dados - pode ser tanto quantitativa, quanto qualitativa;

(4) forma de avaliação - os instrumentos utilizam mais de uma forma de avaliação;

(5) apresentação dos resultados - os instrumentos trazem também diversas formas de apresentação das informações, tanto na fase de preenchimento, quanto na fase de tabulação dos resultados.

Vale observar que os instrumentos avaliativos apresentam tanto pontos positivos, quanto pontos negativos. Merecem destaque os seguintes pontos positivos: clareza durante a aplicação; seqüência lógica; tamanho adequado; clareza na geração dos resultados. Entretanto, os itens exemplos de aplicação com usuários e apresentação de passo-a-passo para aplicação podem ser considerados pontos frágeis dentre os instrumentos avaliativos analisados. (tabela 1) 
Tabela 1: Síntese dos pontos positivos e negativos do instrumento avaliativo

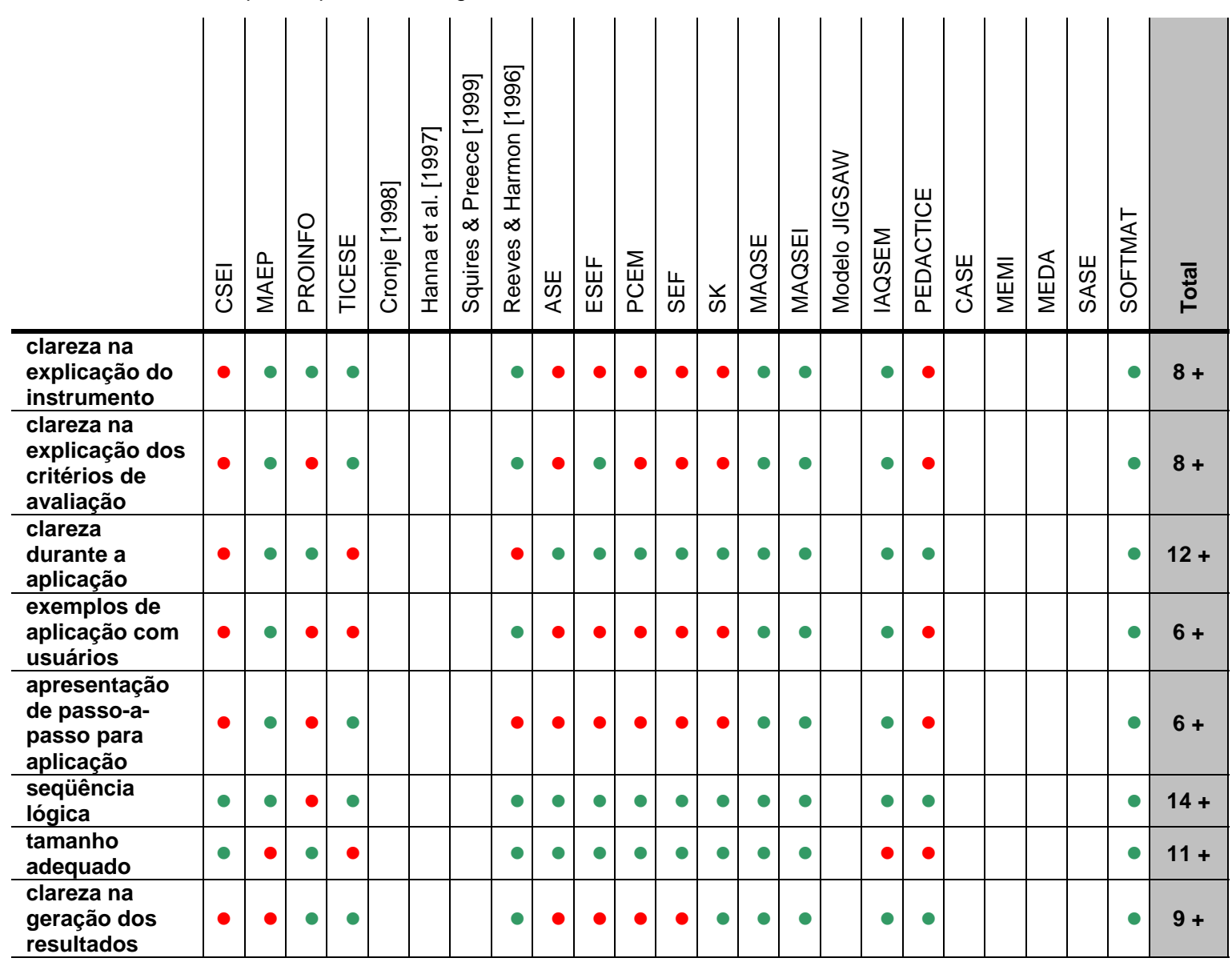

legenda:

$[\bullet]$ pontos positivos

$[\bullet]$ pontos negativos

\section{O papel dos stakeholders na avaliação de software educativo}

A avaliação de software educativo envolve um conjunto de stakeholders, ou seja, indivíduos que têm participação no processo de desenvolvimento ou avaliação de um produto (influência direta ou indireta) ou são afetadas pelo sistema [Freire, 2005]. No caso dos softwares educativos, há três perfis de stakeholders que se destacam:

- Designer (produtor) - desenvolve os softwares e os utiliza para a realização de testes de funcionamento ou avaliação das interfaces;

- Professor (usuário indireto) - participa como um tipo de facilitador/mediador na interação entre os alunos e o software educativo;

- Aluno (usuário direto) - público alvo dos softwares educativos, ou seja, quem interage com a ferramenta realizando atividades que promovam o aprendizado de conceitos.

Apesar do professor não ser o público alvo principal dos softwares educativos, ele julgará se o software é viável para utilização no contexto educacional, ou seja, seu envolvimento pode trazer importantes benefícios para o design. Cybis [2003] identificou três possibilidades de envolvimento dos usuários no design:

- Informativo - o usuário é visto como fonte de informação, ou seja, o usuário fornece informações para o projeto através de entrevistas, questionários ou de observações.

- Consultivo - o usuário é consultado sobre decisões de projeto, para que as verifique e emita opinião. Também pode envolver entrevistas, questionários e observações.

- Participativo - a responsabilidade do projeto é transferida ao usuário, que se torna um 
colaborador. Cabe ao designer incorporar adequadamente os resultados nas soluções de design.

Portanto, nesta pesquisa, o usuário/ stakeholder (o professor), através de envolvimento participativo trouxe comentários, críticas e sugestões para melhorar os métodos, instrumentos e ferramentas de avaliação de software educativo. Os métodos, técnicas e procedimentos empregados na coleta de dados junto aos professores são descritos a seguir.

\section{Método da pesquisa}

Visando propor diretrizes para o desenvolvimento de instrumentos avaliativos de software educativo direcionados para professores do ensino fundamental e médio, o presente estudo adotou uma abordagem de design centrado no usuário, envolvendo os próprios professores na avaliação de instrumentos avaliativos existentes. A figura 7 representa, de forma esquemática, um panorama das 3 (três) etapas da pesquisa com seus respectivos objetivos e técnicas de coleta.

Figura 7: Esquema visual do método da pesquisa

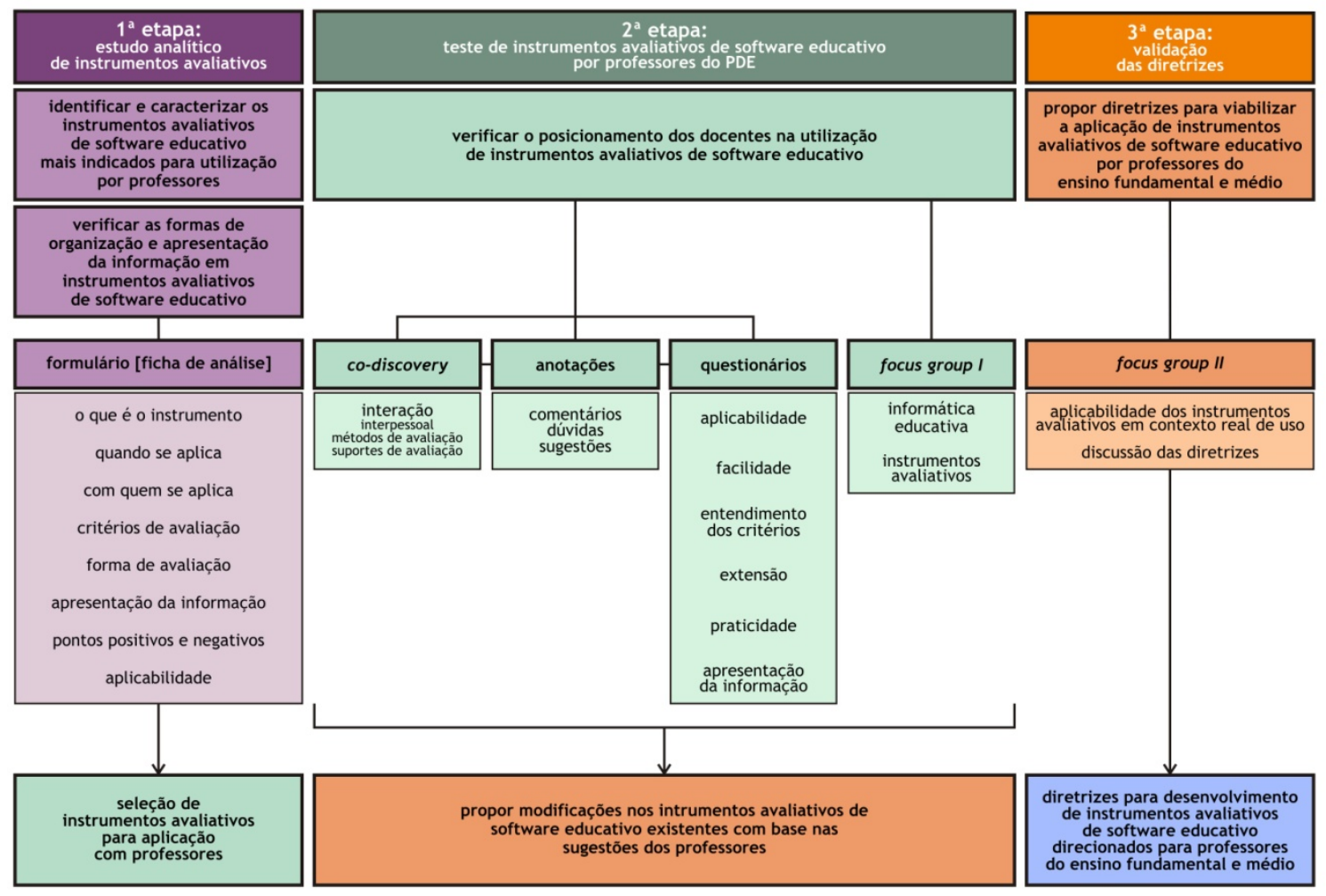

legenda

$\square 1^{\text {a }}$ etapa da pesquisa $\square 2^{\text {a }}$ etapa da pesquisa $\square 3^{\text {a }}$ etapa da pesquisa $\quad \square$ resultado da pesquisa

\section{$1^{\text {a }}$ Etapa: estudo analítico de instrumentos avaliativos de software educativo}

O principal objetivo desta etapa da pesquisa foi identificar e caracterizar os instrumentos avaliativos mais indicados para utilização por professores. A técnica de coleta de dados utilizada foi um formulário com o seguinte roteiro: o que é o instrumento, quando se aplica, com quem se aplica, critérios de avaliação, forma de avaliação, apresentação da informação, síntese dos pontos positivos e negativos e aplicabilidade dos resultados.

Os resultados do estudo analítico permitiram identificar que instrumentos poderiam ser aplicados pelos professores na $2^{\mathrm{a}}$ etapa da pesquisa.

\section{$2^{\text {a }}$ Etapa: teste de instrumentos avaliativos de software educativo por professores}

Esta etapa teve como objetivo verificar o posicionamento dos docentes na utilização de instrumentos avaliativos de software educativo. Desta forma, realizamos uma série de encontros com um grupo de professores para testar os seis instrumentos selecionados no estudo analítico: 
- 2 checklists - Maep (Método ergopedagógico interativo de avaliação para produtos educacionais informatizados) [Silva, 2002] e Proinfo (Programa Nacional de Informática na Educação);

- 1 escala de avaliação - [Reeves \& Harmon, 1996];

- 1 formulário - PCEM (PCEM - Plantilla para la Catalogación y Evaluación. Multimedia [Graells, 2001];

- 1 questionário - Pedactice (Modelo de Avaliação de Software Educativo) [Costa, 1999];

- 1 instrumento avaliativo híbrido - MAQSE (Metodologia para Avaliação da Qualidade de Software Educativo) [Campos, 1994].

Tabela 1: Procedimentos para aplicação dos instrumentos avaliativos e número de participantes

\begin{tabular}{|c|c|c|}
\hline participantes & encontros & explicação \\
\hline 10 & $\begin{array}{l}\text { (1, } 2 \text { e 3) } \\
\text { aplicação e } \\
\text { avaliação dos } \\
\text { instrumentos }\end{array}$ & $\begin{array}{l}\text { Explicação e distribuição dos instrumentos avaliativos (2 } \\
\text { instrumentos por encontro) para os participantes. } \\
\text { Aplicação dos instrumentos avaliativos pelos professores na } \\
\text { avaliação de objetos de aprendizagem de sua escolha (de acordo } \\
\text { com sua área de formação) disponíveis na RIVED (Rede } \\
\text { Internacional Virtual de Educação). } \\
\text { Professores iniciam a avaliação do objeto de aprendizagem } \\
\text { escolhido utilizando os instrumentos avaliativos disponibilizados. } \\
\text { Professores trabalham em duplas, discutindo durante a aplicação - a } \\
\text { esta técnica dá-se o nome de co-descoberta (co-discovery method). } \\
\text { Assim como, realizando anotações durante a aplicação de cada } \\
\text { instrumento avaliativo. } \\
\text { Professores respondem (individualmente) questionário de avaliação } \\
\text { de cada instrumento avaliativo aplicado. }\end{array}$ \\
\hline 10 & $\begin{array}{l}\text { (4) } \\
\text { discussão }\end{array}$ & $\begin{array}{l}\text { No primeiro focus group os participantes foram questionados sobre } \\
\text { informática educativa e os instrumentos avaliativos de softwares } \\
\text { educativos aplicados durante os três encontros anteriores. }\end{array}$ \\
\hline
\end{tabular}

Após os encontros com os participantes foi realizado o primeiro grupo focado (focus group), no qual os participantes foram questionados sobre informática educativa e os instrumentos avaliativos de software educativo.

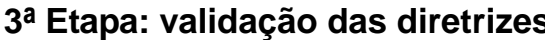

A terceira e última etapa da pesquisa teve como objetivo propor modificações nos instrumentos avaliativos existentes com base nas sugestões dos professores. Em um primeiro momento, retornamos ao grupo de professores a análise geral dos resultados obtidos, explicando as diretrizes propostas e discutindo possíveis alterações/ajustes. Esta discussão foi conduzida em um segundo focus group (figura 8). 
Figura 8: Exemplo de diretriz apresentada aos professores para discussão no segundo grupo focado

1 Quem deve aplicar o instrumento avaliativo

Os instrum entos avaliativos devem ser aplicados pelos próprios professores, pois precisam de instrumentos direcionados, ou seja, com aspectos tanto de usabilidade, quanto de aprendizagem.

- Devem ser aplicados por professores e também desenvolvidos para professores, ou seja, devem ter uma linguagem acessivel, além de conteúdo direcionado para as necessidades dos professores.

- Devem fornecer parâmetros de orientação para auxiliar a tomada de decisão sobre a escolha do material didático digital.

- A literatura apresenta diversos instrumentos avaliativos que podem tam bém ser usados pelos professores, mas nenhum especificamente voltado para as necessidades do professor.

Dos 23 (vinte e três) instrum entos avaliativos a nalisados, encontrados na literatura, 14 (quatorze) provêm da áre
de educaçăo. Metade desses instrum entos năo tem exp licitam ente base em pesquisa cientifica, mas sim, săo resultados de trabalhos com base na experiência do próprio autor.

Após a realização do segundo grupo focado e análise geral dos resultados, diretrizes foram propostas para facilitar a aplicação dos instrumentos avaliativos de software educativo por professores, conjugando resultados empíricos e subsídios teóricos de três áreas de conhecimento: design da informação, ergonomia e educação.

Vale lembrar que os resultados completos das etapas da pesquisa estão publicados em:

- $1^{\text {a }}$ Etapa: estudo analítico de instrumentos avaliativos de software educativo - Godoi [2009];

- $2^{\mathrm{a}}$ Etapa: teste de instrumentos avaliativos de software educativo por professores - Godoi, Padovani \& Haracemiv [2008], Godoi [2009], Godoi \& Padovani [2009];

- $\quad 3^{a}$ Etapa: validação das diretrizes - Godoi [2009].

\section{Diretrizes para o desenvolvimento de instrumentos avaliativos direcionados para software educativo}

De modo a uniformizar e facilitar o entendimento e utilização das diretrizes no desenvolvimento / aplicação de instrumentos avaliativos, todas seguiram o mesmo formato: (1) enunciado da diretriz, (2) justificativa da necessidade da diretriz e (3) comentários dos professores que corroboram a proposta de diretriz. A seguir apresentamos as diretrizes geradas com base no estudo analítico, teste dos instrumentos pelos professores e grupos focados.

\section{D1 | Quem deve aplicar o instrumento avaliativo}

\section{Diretriz}

- Os instrumentos avaliativos devem ser aplicados pelos próprios professores, pois precisam de instrumentos que lhes permitam selecionar material didático digital, incluindo tanto aspectos de usabilidade quanto de aprendizagem.

\section{Justificativa}

- A literatura apresenta diversos instrumentos avaliativos que podem também ser usados pelos professores, mas nenhum especificamente voltado para as necessidades do professor. Por isso, os instrumentos avaliativos devem ser aplicados por professores e também desenvolvidos para professores, ou seja, devem ter uma linguagem acessível, além de conteúdo direcionado para as necessidades dos professores, fornecendo parâmetros de orientação para auxiliar a tomada de decisão sobre a escolha do material didático digital.

\section{Comentários dos professores}

- Os professores participantes da pesquisa foram unânimes em responder (segundo grupo focado) que quem deve aplicar o instrumento avaliativo são eles próprios e não 
especialistas externos à disciplina ministrada ou mesmo ao ambiente escolar.

\section{D2 | Quando o instrumento avaliativo deve ser aplicado}

\section{Diretriz}

- O instrumento avaliativo deve ser somativo e prognóstico (antes da utilização pelos alunos, quando os professores estão planejando suas lições).

\section{Justificativa}

- A avaliação somativa e prognóstica auxilia o professor na escolha do software educativo antes da utilização dos alunos em sala de aula, quando os professores estão em fase de planejamento, servindo como ferramenta de apoio aos professores, para ter condições de explorar previamente o material didático digital.

\section{Comentários dos professores}

- Durante o segundo grupo focado, os professores reafirmaram a inexistência de instrumentos avaliativos na realidade atual, e sugeriram que os cursos de formação de professores deveriam inserir em seus currículos conteúdos relacionados à questão de avaliação de softwares educativos.

- Desta forma, os professores confirmam a importância dos instrumentos avaliativos no contexto de sala de aula e acreditam que seja necessária uma avaliação somativa e prognóstica, ou seja, uma avaliação que o professor possa aplicar antes de utilizar o software em sala de aula. Um professor relatou: "O professor deve avaliar o software antes de utilizar com o aluno. Ele precisa conhecer e saber se aquilo que está proposto ali está de acordo com o que ele quer fazer durante a aula".

- Um dos professores participantes da pesquisa acredita também que a avaliação deva ser somativa, mas realizada antes (prognóstica), durante e depois da aplicação com os alunos. O professor explicou: "Antes para avaliar se o software é pertinente para o que o professor pretende desenvolver em sala de aula. Durante, porque o professor vai observar qual a atitude dos alunos, qual a motivação dos alunos e também as dificuldades, além dos comentários que os alunos venham a fazer sobre o software educativo. $E$ depois, para o professor verificar se o que ele pretendia foi alcançado com sucesso".

\section{D3 | Etapas de aplicação}

Diretriz

- Os instrumentos avaliativos devem trazer especificado as etapas de aplicação, ou seja, passo-a-passo de como deve ser feita a avaliação.

\section{Justificativa}

- Para poder auxiliar o professor no momento da avaliação, assim como tabulação e representação dos resultados, as etapas de aplicação devem incluir os seguintes passos básicos:

(1) reconhecer o software educativo: sugere-se que o avaliador, o professor, tenha um primeiro contato com o software educativo de forma a compreender suas especificidades e o seu funcionamento.

(2) reconhecer e classificar o instrumento avaliativo: sugere-se que o avaliador, o professor, faça uma leitura prévia do instrumento avaliativo. Assim como, uma classificação do instrumento avaliativo conforme mencionados por Godoi e Padovani [2008]: checklist, diretrizes, escala de avaliação, formulário, híbrido, modelo conceitual, questionário e sistema.

(3) avaliar o software educativo: após ter reconhecido o software, reconhecido e classificado o instrumento avaliativo, o avaliador (professor) poderá dar início à avaliação do software educativo. 
(4) tabular dados: esta etapa implica em sub-atividades, dependendo da especificidade do instrumento avaliativo (atribuição de média, peso, porcentagem, valor, interpretação da nota, relato escrito).

(5) representar resultados: com os resultados o avaliador (professor) poderá construir uma representação, dependendo da especificidade de cada instrumento avaliativo (perfil em diferencial semântico, gráfico comparativo, planilha eletrônica, tabela, texto).

\section{Comentários dos professores}

- Os professores participantes do segundo grupo focado acreditam que seja importante que existam as etapas de aplicação e as devidas explicações sobre como utilizar o instrumento avaliativo. Também consideraram que as etapas são coerentes e completas. Entretanto, os professores observaram que para o dia-a-dia, ou seja, para a realidade deles, talvez não utilizassem o instrumento avaliativo de forma tão fechada.

\section{D4 | Apresentação de exemplo de aplicação com usuários}

\section{Diretriz}

- O instrumento avaliativo deve trazer exemplos de aplicação com usuários.

\section{Justificativa}

- O exemplo de aplicação com o usuário é importante, pois auxiliará o professor a entender melhor que procedimentos deve tomar para proceder à avaliação de um material didático digital.

\section{Comentários dos professores}

- Os professores acreditam que seja importante uma apresentação de exemplo de aplicação com usuários, levando em consideração que durante a pesquisa, na aplicação dos instrumentos avaliativos, sentiram dificuldade de entender alguns instrumentos avaliativos, por não trazerem exemplos de aplicação com usuários.

\section{D5 | Critérios para avaliação do software educativo}

\section{Diretriz}

- Os instrumentos avaliativos devem conter critérios ergonômicos (de interface) e pedagógicos (de aprendizagem).

\section{Justificativa}

- Todos os instrumentos avaliativos analisados usam critérios ergonômicos e pedagógicos, ou seja, combinam critérios para que o usuário possa utilizar a tecnologia com segurança e conforto, tendo em vista os objetivos educacionais. Os critérios, por sua vez, devem abarcar uma avaliação global, sob vários aspectos do software (p. ex. controle do utilizador, documentação de apoio, feedback, flexibilidade, funcionalidade geral, gestão de erros, identificação do software, qualidade das opções de ajuda, usabilidade da interface, avaliação da aprendizagem, conteúdo, motivação), funcionando como um guia que conduz o professor na avaliação.

\section{Comentários dos professores}

- Os professores participantes do segundo grupo focado concordaram que os critérios devem abarcar uma avaliação global. Um professor explicou: "Esses critérios ajudam o professor, informando e aperfeiçoando seu conhecimento, até como um conteúdo, não só para avaliar, mas para o professor conhecer determinados aspectos, sobre os quais às vezes não foi informado".

\section{D6 | Categorias/ módulos de agrupamento dos critérios de avaliação}




\section{Diretriz}

- O instrumento avaliativo deve possuir categorias/ módulos de agrupamento dos critérios de avaliação, para que o professor tenha clareza durante a aplicação (durante a utilização do instrumento avaliativo).

\section{Justificativa}

- A divisão dos critérios por categorias/ módulos auxilia e orienta o professor na localização dos critérios, facilitando o uso do instrumento avaliativo. O estudo analítico apontou três agrupamentos principais: dados técnicos do software educativo, critérios ergonômicos e critérios pedagógicos.

\section{Comentários dos professores}

- Durante a pesquisa com os professores, os mesmos destacaram a importância da divisão/ organização dos critérios em grupos de análise. Observamos também, através das respostas dos professores, que as categorias são importantes, pois auxiliam e orientam o professor na localização dos critérios, assim como, na divisão/ organização dos critérios em grupos de análise.

\section{D7 | Explicação dos critérios adotados}

Diretriz

- Os instrumentos avaliativos devem conter explicações claras e sucintas dos critérios adotados.

\section{Justificativa}

- A explicação dos critérios auxilia o professor no entendimento do que está sendo avaliado, por isso a linguagem deve ser apropriada para o professor. Durante a pesquisa com professores pudemos constatar que os termos técnicos empregados relacionados à ergonomia e à informática não são familiares aos professores. Desta forma, a explicação dos critérios deve tornar o instrumento avaliativo fácil de usar (com questões, critérios e explicações fáceis, simples e breves).

\section{Comentários dos professores}

- Os professores concordaram que os instrumentos avaliativos devem conter explicações claras e sucintas dos critérios adotados. Mencionaram que a explicação dos critérios auxilia o professor no entendimento do que está sendo avaliado, por isso a linguagem deve ser apropriada para o professor.

\section{D8 | Forma(s) adicional(is) de esclarecer dúvidas}

\section{Diretriz}

- Os instrumentos avaliativos devem conter alguma forma adicional de esclarecer dúvidas, por exemplo através de e-mail ou website.

\section{Justificativa}

- A forma adicional de esclarecer dúvidas auxilia o professor no esclarecimento de eventuais problemas durante a aplicação do instrumento avaliativo.

\section{Comentários dos professores}

- Os professores aprovaram essa diretriz e sugeriram que além do instrumento avaliativo impresso, também deveria existir um equivalente virtual, com um serviço de perguntas mais freqüentes (FAQs).

\section{D9 | Forma de avaliação e apresentação das informações na fase de preenchimento}




\section{Diretrizes}

- Os instrumentos avaliativos devem conter mais de uma forma de avaliação do software educativo em cada uma das questões (p. ex. binária e escala numerada).

- O instrumento avaliativo deve conter perguntas fechadas.

- A forma de apresentação das informações na fase de preenchimento deve ser híbrida, ou seja, contendo texto e mais uma outra forma (p. ex. tabela).

\section{Justificativas}

- As perguntas devem ser curtas, de fácil entendimento e leitura, para que os professores possam aplicar os instrumentos avaliativos rapidamente.

- A forma híbrida diversifica e dinamiza mais a apresentação das informações na fase de preenchimento.

\section{Comentários dos professores}

- No segundo grupo focado, os professores concordaram que os instrumentos avaliativos devem conter mais de uma forma de avaliação do software educativo em cada uma das questões, ou seja, deve ser híbrida. Um professor comentou: "Eu acho que dependendo do critério muitas vezes um tipo de forma de avaliação não é suficiente para responder, então eu acho que é importante conter mais de uma forma."

- Além de conter mais de uma forma de avaliação do software educativo em cada uma das questões, o resultado da aplicação dos instrumentos avaliativos com os professores mostrou a preferência por perguntas fechadas. Entretanto, no grupo focado os professores demonstraram maior flexibilidade e sugeriram que as questões sejam fechadas, mas que sim e não poderiam ser substituídas por uma escala de intensidade, ou seja, com mais opções de respostas. E o instrumento avaliativo deveria ter a possibilidade de colocar algum comentário caso houvesse necessidade. Um professor explicou: "Aí algumas questões que você... de repente tem mais dificuldade $e$ você acha que são importantes, um espaço para uma observação a mais, por exemplo, com a possibilidade de colocar num mesmo quadro."

- Os professores concordaram sobre a forma de apresentação das informações na fase de preenchimento ser híbrida e comentaram que facilita bastante. Os professores comentaram que acham interessante como está no checklist MAEP, pois a forma de apresentação das informações na fase de preenchimento é compreensível e simples, devido à organização/ estruturação/ agrupamento dos critérios, assim como as hierarquias estabelecidas (hierarquia alfanumérica e de cores).

\section{D10 | Ênfase na coleta/análise dos dados}

\section{Diretriz}

- A ênfase na coleta/ análise dos dados deve ser tanto quantitativa quanto qualitativa.

\section{Justificativa}

- Durante a pesquisa com professores, observamos a necessidade de instrumentos avaliativos quantitativos possuir espaços para dados qualitativos, ou seja, para que os professores pudessem expressar suas opiniões.

\section{Comentários dos professores}

- A discussão dessa diretriz gerou em torno da ênfase na coleta/ análise dos dados. Observamos que os professores já haviam respondido essa diretriz anteriormente. De qualquer forma, os professores confirmaram a preferência na coleta/ análise dos dados ser tanto quantitativa, quanto qualitativa. Pois, tanto na aplicação dos instrumentos avaliativos com professores, quanto nos grupos focados, observamos a necessidade de instrumentos avaliativos quantitativos possuírem espaços para dados qualitativos, ou seja, para que os professores pudessem expressar suas opiniões. 


\section{D11 | Forma de apresentação das informações na tabulação dos resultados}

\section{Diretrizes}

- A forma de tabulação/ totalização dos resultados deve ser prática e simples, devendo permitir identificação (imediata) de pontos positivos e falhas no software educativo.

- A apresentação das informações na tabulação dos resultados deve ser de forma visual, ou seja, através de gráficos, perfil em diferencial semântico, etc.

\section{Justificativas}

- A forma de tabulação/ totalização deve auxiliar o professor (precisa ser prático e rápido), ou seja, não é recomendado o uso de peso e porcentagem, a não ser que esta última seja de forma automática (sistema ou planilha eletrônica).

- A apresentação das informações na tabulação dos resultados auxilia os professores facilmente e rapidamente na interpretação dos resultados (identificação precisa do problema do material didático digital).

\section{Comentários dos professores}

- Os professores participantes da pesquisa concordaram que a forma de tabulação/ totalização das informações precisa ser perceptível rapidamente.

- Os professores também acreditam que a apresentação das informações na tabulação dos resultados deve ser de forma visual, ou seja, através de gráficos, perfil em diferencial semântico, etc. Os professores recordaram a forma de apresentação das informações na tabulação dos resultados na escala de Revees e Harmon [1996].

- De qualquer maneira, as formas visuais de apresentação auxiliam os professores facilmente e rapidamente na interpretação dos resultados (identificação precisa do problema do material didático digital).

\section{D12 | Forma de disponibilização do instrumento avaliativo}

\section{Diretriz}

- O instrumento avaliativo deve estar disponível nos dois formatos, tanto impresso quanto digital.

\section{Justificativa}

- Devem existir as duas possibilidades, para atender tanto aos professores que estão familiarizados com formatos digitais, quanto professores que estão acostumados com o formato impresso.

\section{D13 | Possibilidade de customização do instrumento avaliativo}

Diretriz

- O instrumento avaliativo dever possibilitar customização em diversos aspectos do instrumento, ou seja, o professor deveria ter liberdade para escolher: os critérios; se quantitativo ou qualitativo; apresentação das informações na apresentação dos resultados.

- Instrumento avaliativo para o dia-a-dia. Deve ser rápido e prático nas questões. O instrumento avaliativo para o dia-a-dia não deve demandar muito tempo do professor. Não deve ser extenso, pois torna-se cansativo. Deve ser ter um preenchimento ágil.

- Instrumentos avaliativos para reuniões pedagógicas. Os instrumentos avaliativos mais extensos devem ser abrangentes, ter um nível maior de detalhamento e também possuir critérios para o desenvolvimento de softwares. Poderão auxiliar os professores na elaboração/ organização de conteúdos. 
- Deve-se permitir ao professor construir sua própria grade de avaliação (sob medida), adaptada às necessidade de avaliação identificadas por cada um.

\section{Comentários dos professores}

- Os professores mencionaram que sempre deve ser levado em consideração o perfil do usuário (professor). Desta maneira, acredita-se que o instrumento avaliativo deva possibilitar o professor a construir sua própria grade de avaliação (sob medida), adaptada às necessidades de avaliação identificadas por cada um. Um professor mencionou:

- Eu acho legal, porque às vezes desanima ter que pensar que precisamos passar por todos os critérios e de repente para um determinado momento precisamos só saber se atende um ou dois critérios.

- Por fim, concordaram com a possibilidade de customização de um instrumento avaliativo para o dia-a-dia, o qual deve ser rápido e prático nas questões; e outro instrumento avaliativo para reuniões pedagógicas, o qual deve ser mais extenso e abrangente, ou seja, com um nível maior de detalhamento.

\section{D14 | Manual de instruções e glossário}

\section{Diretrizes}

- O instrumento avaliativo deve possuir um manual de instruções.

- O instrumento avaliativo deve conter um glossário com explicação dos termos técnicos.

\section{Justificativas}

- O manual de instruções auxilia o professor em todos os passos durante a avaliação: entendimento dos objetivos do instrumento avaliativo, quando o instrumento avaliativo deve ser aplicado, etapas de aplicação, categorias/ módulos de agrupamento dos critérios de avaliação, os critérios adotados para avaliação, explicação dos critérios adotados, formas de esclarecer dúvidas, forma(s) de avaliação em cada questão, forma(s) de tabulação/ totalização dos resultados, possibilidade de customização do instrumento avaliativo.

- O glossário foi sugestão dos professores, desta forma, auxiliará na compreensão/ esclarecimento de termos técnicos de outras áreas do conhecimento (p. ex. ergonomia e informática).

\section{Comentários dos professores}

- Os professores concordaram com o manual de instruções. Este manual ajudará o professor em todos os passos durante a avaliação. Os professores também concordaram que o instrumento avaliativo deve conter um glossário com explicação dos termos técnicos, para auxiliar na compreensão dos termos técnicos de outras áreas do conhecimento, como por exemplo: ergonomia e informática.

\section{Conclusões e desdobramentos}

Durante a pesquisa, procuramos compreender melhor os instrumentos avaliativos direcionados para avaliação de softwares educativos, para que esses instrumentos pudessem atender melhor às necessidades dos professores. Observamos claramente a existência de uma lacuna entre a presença de instrumentos avaliativos de software educativo na literatura e a falta de conhecimento desses instrumentos por parte dos professores. Desta forma, iniciamos uma aproximação desses mecanismos de apoio aos professores.

Uma abordagem centrada no usuário neste processo foi providencial, na medida em que toma as necessidades e expectativas dos usuários o foco central para o desenvolvimento de diretrizes para instrumentos avaliativos.

Assim, através destas contribuições, este trabalho espera poder colaborar para novas pesquisas em duas frentes: no design participativo de instrumentos avaliativos, e na estruturação 
de um novo e/ou adaptado instrumento avaliativo que esteja preocupado com questões levantadas pelos próprios professores e, portanto, compatível com suas necessidades.

Por fim, como desdobramentos desta pesquisa podemos ter: desenvolvimento de um novo instrumento avaliativo direcionado para professores, a partir das diretrizes propostas; aplicação com professores de instrumentos avaliativos adaptados conforme as diretrizes propostas; e modificar a mídia atual (impresso) predominante na disponibilização dos instrumentos avaliativos para um sistema interativo.

\section{Referências}

Buckleitner, W. Children's Software Evaluation Instrument. 1998. Disponível em: <http://www.childrenssoftware.com/rating.html> Acesso em: nov. 2007.

Campos, G. H. B. de. 1994. Metodologia para avaliação da qualidade de software educacional. Diretrizes para desenvolvedores e usuários. Rio de Janeiro, 1994. 232 f. Tese (Doutorado em Engenharia de Produção), Universidade Federal do Rio de Janeiro, Rio de Janeiro.

Costa, F. 1999. Pedactice: educational multimedia in school. Disponível em: <http://www.fpce.ul.pt/projectos/pedactice> Acesso em: junho 2007.

Cybis, W. de A. 2003. Engenharia de usabilidade: uma abordagem ergonômica. Florianópolis: Laboratório de Utilizabilidade de Informática/UFSC.

Freire, L. L.. 2005. Navegação e design em softwares educativos: uma abordagem ergonômica. Recife, 2005. 345 f. Dissertação (Mestrado em Design) - Centro de Artes e Comunicação, Universidade Federal de Pernambuco.

Gamez, Luciano. TICESE: técnica de inspeção de conformidade ergonômica de software educacional. Manual do avaliador. Porto, 1998. 45 f. Parte de Dissertação (Mestrado em Engenharia Humana), Universidade do Minho, Porto, 1998.

Graells, P. M. 2001. Plantilla para la Catalogación y Evaluación Multimedia. Disponível em: <http://dewey.uab.es/pmarques/dim/revistadigital/dimavam0.rtf> Acesso em: set. de 2007.

Godoi, K. A. 2009. Validação participativa de instrumentos avaliativos de software educativo por professores do ensino fundamental e médio. Curitiba, 2009. 219 f. Dissertação (Mestrado em Design) - Setor de Ciências Humanas, Letras e Artes, Universidade Federal do Paraná, Curitiba.

Godoi, K. A.; Padovani, S.; Haracemiv, S.M. C. 2008. Métodos direcionados para avaliação de software educativo e sua utilização por professores. In: XVIII Afirse. Lisboa.

Godoi, K. A. \& Padovani, S. 2009. Estudo analítico de checklists para avaliação de software educativo. In: Ulbricht, V. R. \& Pereira, A. T. C. (orgs.). Hipermídia: um desafio da atualidade. Florianópolis: Pandion.

Godoi, K. A. \& Padovani, S. Avaliação de material didático digital centrada no usuário: uma investigação de instrumentos passíveis de utilização por professores. Prod. [online]. 2009, vol.19, n.3, pp. 445-457.

ISTE International Society for Technology in Education. Educational Software Evaluation Form. 2002. Disponível em: <http://cnets.iste.org/teachers/web/t_form_software-eval.html> Acesso: abril 2007

Proinfo - Programa Nacional de Informática na Educação. Checklist. In: Encontro Nacional do Proinfo, 3. Disponível em: < http://www2.uel.br/seed/nte/analisedesoftwares.html> Acesso em: out. 2007.

Reeves, T. C. \& Harmon, S. 1996. Systematic evaluation procedures for interactive multimedia for education and training. In: Reisman, Sorel. Multimedia Computing: preparing for the 21st Century. Hershey, PA: Idea Group Publishing: 472-582.

Shiratuddin, N. \& Landoni, M. 2002. Evaluation of content activities in children's educational software. Evaluation and Program Planning, v. 25, n.2: 175-182.

Silva, C. R. de O. 2002. MAEP: um método ergopedagógico interativo de avaliação para produtos educacionais informatizados. Florianópolis, 2002. 224 f. Tese (Doutorado em Engenharia de 
Produção), Universidade Federal de Santa Catarina, Florianópolis.

Squires, D. \& Preece, J. 1999. Predicting quality in educational software: evaluating for learning, usability and synergy between them. Interacting with Computers, v. 11, n.5: 467-483.

\section{Sobre as autoras}

Katia Alexandra de Godoi é graduada em Desenho Industrial pela FAAP (1993), especialista em Didática do Ensino Superior pela PUC-PR (1997), mestre em Design pela UFPR (2009) e doutoranda do PPGEducação: Currículo da PUC-SP. Suas principais áreas de interesse são: design da informação, ergonomia da interação humano-computador e educação, com enfoque nos métodos/ instrumentos de avaliação de softwares educativos. <katigodoi@gmail.com>

Stephania Padovani é graduada em Desenho Industrial pela ESDI-UERJ (1996), mestre em Design pela PUC-RJ (1998) e doutora em Ergonomia Cognitiva pela Loughborough University I Inglaterra (2001). É bolsista de Produtividade em Pesquisa do CNPq [nível 2], professora e pesquisadora do Departamento de Design e do Programa de Pós-graduação em Design da UFPR. Suas principais áreas de atuação são ergonomia da interação humano-computador, web design e design da informação, com enfoque nos temas de hipermídia, usabilidade de interfaces e métodos de design centrado no usuário. <s_padovani2@yahoo.co.uk> 